\title{
Continuous Disinfection by Monochloramine on Domestic Hot Water System of Health-care Facilities for the Control of Legionella Contamination in Italy
}

\author{
Maria Anna Coniglio ${ }^{1,3}$, Nunzia Andolfi ${ }^{2}$, Giuseppina Faro ${ }^{3}$, Maria Beatrice Pellegrino ${ }^{2}$, Angela Sgalambro ${ }^{2}$, \\ Giuseppe D'Aquila ${ }^{4}$, Alfio Spina ${ }^{5}$ and Stefano Melada ${ }^{6}$ \\ 1.Legionella Reference Laboratory, Department of Medical, Surgical Sciences and Advanced Technologies "G.F. Ingrassia", \\ University of Catania, Catania 95123, Italy \\ 2. Public Health Laboratory LSP, ASP8, Siracusa, Italy \\ 3. Department of Medical, Surgical Sciences and Advanced Technologies "G.F. Ingrassia”, University of Catania, Catania 95123, Italy \\ 4. Hospital 'Umberto I', ASP8, Siracusa 96100, Italy \\ 5. Hospital 'Nuovo Ospedale di Lentini', ASP 8, Lentini (Siracusa), Italy \\ 6. Sanipur srl, Flero (BS) 25020, Italy
}

Received: February 11, 2015 / Accepted: February 28, 2015 / Published: February 28, 2015.

\begin{abstract}
Backgroud: The prevention of Legionella spp. colonization of water distribution systems is a critical issue in healthcare settings and only an effective disinfection of water systems and appropriate environmental surveillance strategies allow to prevent nosocomial legionellosis. Methods: Due to the temporary effectiveness (increase of the temperature of water in boilers and shock hyperchlorination), the high costs (point-of-use water filters) or the ineffectiveness (hydrogen peroxide, $\mathrm{H}_{2} \mathrm{O}_{2}$ ) of the previous control procedures, 3 devices (one for each hot water loop) continuously injecting monochloramine have been installed in two different Italian hospitals heavily contaminated by Legionella pneumophila SG3 and SG6. Aim: To evaluate the efficacy of continuous disinfection by monochloramine for control of Legionella on domestic hot water (DHW) distribution system of health-care facilities. Findings: One month after the disinfection of DHW with monochloramine, the load of L. pneumophila SG3 and SG6 (previous mean count ranging from $10^{3}$ to $10^{5} \mathrm{CFU} / \mathrm{L}$ ), as well as the Heterotrophic Plate Count (HPC) (previous mean count ranging from $>10^{2}$ to $>10^{4} \mathrm{CFU} / \mathrm{mL}$ ), decreased at undetectable levels in $100 \%$ of the sampling points in the two hospitals. Conclusion: The results suggest that continuous injection of monochloramine on DHW systems can fully control L. pneumophila and HPC in contaminated hospitals since the beginning of its application.
\end{abstract}

Keywords: Hospitals, Legionella, monochloramine.

\section{Introduction}

Legionella is an organism of public health interest for its ubiquitous presence in water distribution systems (WDS) and for its ability to cause infection in susceptible humans.

It is well known that factors that most enhance colonization of a WDS include the water temperature,

Corresponding author: Maria Anna Coniglio, M.D., research field: Legionella and legionellosis. E-mail: ma.coniglio@unict.it. piping obstruction and stagnation, biofilm formation and the presence of protozoa, in which legionellae multiply. One of the key issues for controlling the colonization of a WDS is to recommend an effective disinfection method. At present, chlorination is the most commonly used treatment for Legionella control in WDS, but it has been shown that lapses in chlorination or discontinuous chlorination with chlorine or chlorine dioxide can lead to an increased resistance of Legionella to the disinfectant [1]. 

for the Control of Legionella Contamination in Italy

Copper-silver ionization is currently used for Legionella control in WDS in the US, while in Europe copper based products for drinking water disinfection have not been allowed since $1^{\text {st }}$ February 2013 [2].

Among the antimicrobial agents of relatively most recent application in the disinfection of water, monochloramine seems to be more effective for Legionella remediation in hospital plumbing systems [3-5]. The present study shows the results obtained by the continuous injection of monochloramine for 1 year on domestic hot water (DHW) in two Italian hospitals heavily contaminated by Legionella. The effectiveness of monochloramine in controlling Legionella has been compared with other control systems previously adopted.

\section{Methods}

\subsection{Background and Setting}

In 2012, a sampling plan was implemented to assess Legionella contamination of the water systems in two Italian hospitals: the hospital "Umberto I" (Siracusa) and the hospital "Nuovo Ospedale di Lentini" (Lentini, Siracusa).

The hospital "Umberto I" is a very old hospital, built during the period 1930-1960, which comprises two different 5-floors buildings with a total of 350 beds. The "Nuovo Ospedale di Lentini" is a 5-floors building, 150-bed facility built in the 1990s but opened in 2012, thus with a WDS that remained unused for a long period of time. For each hospital incoming cold groundwater, disinfected with chlorine, is provided by two different local Municipalities. DHW is produced and distributed in three different loops: two loops (one for each building with two 2,000 L boilers) at the hospital "Umberto I" and one loop (with three 5,000 L boilers) at the hospital "Nuovo Ospedale di Lentini".

Between 2012 and 2013, 148 hot water samples (96 at the hospital "Umberto I" and 52 at the hospital "Nuovo Ospedale di Lentini") were collected from the boilers, return loops and outlets (faucets and showers selected on the basis of distance from the boilers and exposure risk) of the two hospital WDS. The sampling strategy included DHW loops and at least one ward for each floor, reiterating the same sites every 4 months. In total, 3 boilers with their respective return loops were sampled: 2 at the hospital "Umberto I" (one for each building) and 1 at the "Nuovo Ospedale di Lentini".

High levels of L. pneumophila detected in the two hospitals led to the adoption of a combined control strategy that included the raise of the water temperature in boilers, the performance of shock hyperchlorinations, the installation of point-of-use water filters in the most at risk wards and, in 2013, only at the hospital "Nuovo Ospedale di Lentini", continuous disinfection of the DHW loop with hydrogen peroxide $\left(\mathrm{H}_{2} \mathrm{O}_{2}\right)$.

Eventually, due to the persistence of a strong contamination of the DHW loops, experimental equipments-2 at the hospital "Umberto I" (one for each building) and 1 at the hospital "Nuovo Ospedale di Lentini" - continuously injecting monochloramine (Sanikill patented system, Sanipur Srl, Brescia, Italy) at 2.0-2.5 mg/L were installed at the beginning of 2014 . Monochloramine efficacy for Legionella disinfection was evaluated over a 12-month period.

\subsection{Sample Collection}

After the start of hot water monochloramination, between January 2014 and January 2015, a total of 387 hot water samples (244 at the hospital "Umberto I" and 143 at the hospital "Nuovo Ospedale di Lentini") were monthly collected from the same sites within the DHW networks of the two hospitals. The water samples were collected measuring water temperature and chlorine levels (free chlorine and monochloramine; DPD Free and Monochlor-F methods, HACH Company, USA). Boilers and return loops were collected after a $5 \mathrm{~min}$ flushing and flaming while outlets (taps and showers) were collected without flushing and flaming in accordance with the Italian Guidelines for Legionellosis Prevention [6].

One-liter sterile bottles, added with $1 \mathrm{~mL}$ of sodium thiosulphate in order to neutralize residual free chlorine 
or monochloramine were used for bacteriological analyses. According to ISO 19458 [7], procedures for sample collection, transport and storage were established. Bottles were returned to the laboratory immediately after sampling for bacteriological analyses.

\subsection{Microbiological Analyses}

The water samples were analyzed within $12 \mathrm{~h}$ from collection for the detection of Legionella.

The Heterotrophic Plate Count (HPC) at $22{ }^{\circ} \mathrm{C}$ was detected in PCA (Plate Count Agar-Oxoid) in accordance with ISO 6222 [8] to evaluate the relationship between total microbial concentration and Legionella positivity.

Isolation of Legionella was performed in accordance with standards procedures ISO 11731 [9]. One liter of water from each sampling point was concentrated using $0.2 \mu \mathrm{m}$ filter polyamide membranes (Sartorious). Each membrane was shaken for $15 \mathrm{~min}$ in $10 \mathrm{~mL}$ of the correspondent water sample to detach bacteria. For each water sample, an aliquot of $5 \mathrm{~mL}$ of the concentrated sample underwent immediate cultural examination while the remaining $5 \mathrm{~mL}$ was treated with heat by exposure to $50{ }^{\circ} \mathrm{C}$ for $30 \mathrm{~min}$. From both the samples (concentrated and heat-treated sample), aliquots of $0.1 \mathrm{~mL}$ were inoculated onto one plate of BCYE agar (CYE agar with added BCYE $\alpha$ growth supplement, Oxoid) and $0.1 \mathrm{~mL}$ onto one plate of GVPC agar (BCYE agar with added GVPC selective supplement, Oxoid). After 4,8 and 14 days of incubation at $37{ }^{\circ} \mathrm{C}$ in $2.5 \% \mathrm{CO}_{2}$, colonies suggestive for Legionella grown on BCYE and GVPC were confirmed on the basis of cultural testing (lack of growth on CYE agar) and serogrouped by slide agglutination using commercial antisera (Oxoid and Biogenetics).

Results were expressed in CFU/L and the counts referred to water samples concentrated 100 times $(1 \mathrm{~L}$ in $10 \mathrm{~mL}$ of the water sample). The detection limit of the culture procedure was $10 \mathrm{CFU} / \mathrm{L}(1 \mathrm{CFU} / \mathrm{mL}$ of inoculums corresponds to $1 \mathrm{CFU} / 100 \mathrm{~mL}$ of the untreated sample).

\subsection{Chemical and Physical Analyses}

For each water sample the water temperature (in ${ }^{\circ} \mathrm{C}$ ) was registered at the time of the sampling using a calibrated thermometer placed in the middle of the water stream. $\mathrm{pH}$ and ORP were measured with portable instruments. Total hardness was measured with a titration test kit $(\mathrm{HACH})$. The chemical analyses (free $\mathrm{Cl}_{2}$, total $\mathrm{Cl}_{2}, \mathrm{NH}_{2} \mathrm{Cl}, \mathrm{NH}_{4}^{+}, \mathrm{NO}_{3}^{-}, \mathrm{NO}_{2}{ }^{-}$) were conducted on site with a $\mathrm{HACH} \mathrm{DR} / 900$ portable photometer. All the chemical parameters above were determined before the injection of the monochloramine (baseline) and successively.

\section{Results}

At the beginning of the monitoring programme, in 2012, two years before the installation of the 3 monochlorammine generator devices, a systemic colonization of the water networks was demonstrated. L. pneumophila SG3 and SG6 was isolated from $100 \%$ of the sampling points in the two hospitals (SG3 at the hospital "Umberto I" and SG6 and the hospital "Nuovo Ospedale di Lentini"), with a mean count ranging from $10^{3}$ to $10^{5} \mathrm{CFU} / \mathrm{L}$ and $\mathrm{HPC}$ at $22{ }^{\circ} \mathrm{C}$ ranging from more than $10^{2}$ to more than $10^{4} \mathrm{CFU} / \mathrm{mL}$.

Due to these levels of colonization, first of all the temperature of water in boilers in the two hospitals was raised from $55-60{ }^{\circ} \mathrm{C}$ to $65-70{ }^{\circ} \mathrm{C}$. Following the temperature increase the number of positive supply points for L. pneumophila and the mean bacterial loads decreased immediately but remained stable only for 1 month. For this reason, shock hyperchlorinations (sodium hypochlorite, $50 \mathrm{ppm}$ of free chlorine at distal points for $1 \mathrm{~h}$ ) were performed. After each shock hyperchlorination the number of positive supply points and the mean bacterial loads decreased immediately. Nonetheless, after 3 months L. pneumophila appeared again in all the sampling points. In total, shock hyperchlorinations were performed 4 times, from 2012 

for the Control of Legionella Contamination in Italy

to 2013 , in the two hospitals. In order to control the level of colonization, point-of-use water filters $(0.2 \mathrm{~m}$ sterile filters) were installed in high risk areas, such as haematology, oncology and intensive care units to insure complete protection toward legionellosis to high risk patients.

After the installation of the point-of-use water filters positive sites rate was reduced by $100 \%$, but the filters had to be replaced every 30 days according to the manufacturer's specifications and the entire procedure was extremely expensive. Finally, taking into consideration that the point-of-use water filers had been installed only in selected areas and that 3 months after each shock hyperchlorination Legionella appeared again, at the beginning of 2013 a continuous stabilized $\mathrm{H}_{2} \mathrm{O}_{2}$ system was installed in the DHW system of the hospital "Nuovo Ospedale di Lentini", assuring a minimum concentration, within the limits set by the European Standard EN902: 2009 [10], of 17 $\mathrm{mg} / \mathrm{L}$ of $\mathrm{H}_{2} \mathrm{O}_{2}$. Nonetheless, after 1 year the levels of colonization remained stable. In fact, apart from the distal outlets in which point-of-use water filters had been installed, 3 months after each shock hyperchlorination and during the continuous addition of $\mathrm{H}_{2} \mathrm{O}_{2}$ Legionella returned to the previous concentrations.

The disinfection of the DHW with chlorine dioxide was taken into consideration but it was rejected after the evaluation of its potential corrosive effects on water pipes [11-15].

Moreover, the possibility of using alternative methods like, for example, peracetic acid or U.V. lights were rejected for their documented ineffectiveness in controlling strong levels of colonization [16-18]. Thus, due to the limited effectiveness (increase of the temperature of water in boilers, shock hyperchlorination) or the high costs (point-of-use water filters) or the ineffectiveness $\left(\mathrm{H}_{2} \mathrm{O}_{2}\right)$ of the controlling strategies adopted, at the beginning of 2014 a new control strategy had to be chosen. A scientific literature survey [3-5] and the risk assessment of the two hospitals directed the choice to the monochloramine.

Three monochloramine generator devices were installed in the DHW systems of the two hospitals: 2 at the hospital "Umberto I" (one for each building), and 1 at the hospital "Nuovo Ospedale di Lentini". At the beginning of the disinfection program monochloramine was injected into the DHW at an average concentration of $3 \mathrm{mg} / \mathrm{L}$ for 30 days in order to disinfect the entire water systems. Subsequently, the dosage was regulated to obtain a continuous monochloramination within the range $2.0-2.5 \mathrm{mg} / \mathrm{L}$. Continuous monitoring of oxidation reduction potential (ORP) in the hot water return line and flow rate of supply water to the hot water system were used to control dosage.

One month after the continuous injection of monochloramine, the load of Legionella (Fig. 1), as well as the HPC at $22{ }^{\circ} \mathrm{C}$, decreased at undetectable levels. In particular, at the hospital "Nuovo Ospedale di Lentini", only 1 week after the start of the new disinfection system, the percentages of positive sample points decreased at $8 \%$, with a mean L. pneumophila load lower than $10^{3} \mathrm{CFU} / \mathrm{L}$. In the same hospital, however, as a consequence of a stop of the monochloramine generator device, during which the release of disinfectant was interrupted for around 15 days, Legionella was isolated in all the sampling sites with counts $>10^{5} \mathrm{CFU} / \mathrm{L}$.

Anyway, all samples became negative as soon as the system got back to operation (Fig. 1).

Chemical analyses did not detect changes in the water chemical and physical properties and no specific disinfection by product (DBP) was detected. In particular, as shown on Table 1, ammonium, nitrite and nitrate concentrations did not exceed their limits during the study.

Observed $\mathrm{pH}$ values ranged from 7.8-8.5, while ammonium concentrations ranged from $0.00-0.55 \mathrm{ppm}$, while nitrite concentrations ranged from 0.002-0.040 ppm, and nitrate concentrations ranged from 4.6-25.6 ppm. 


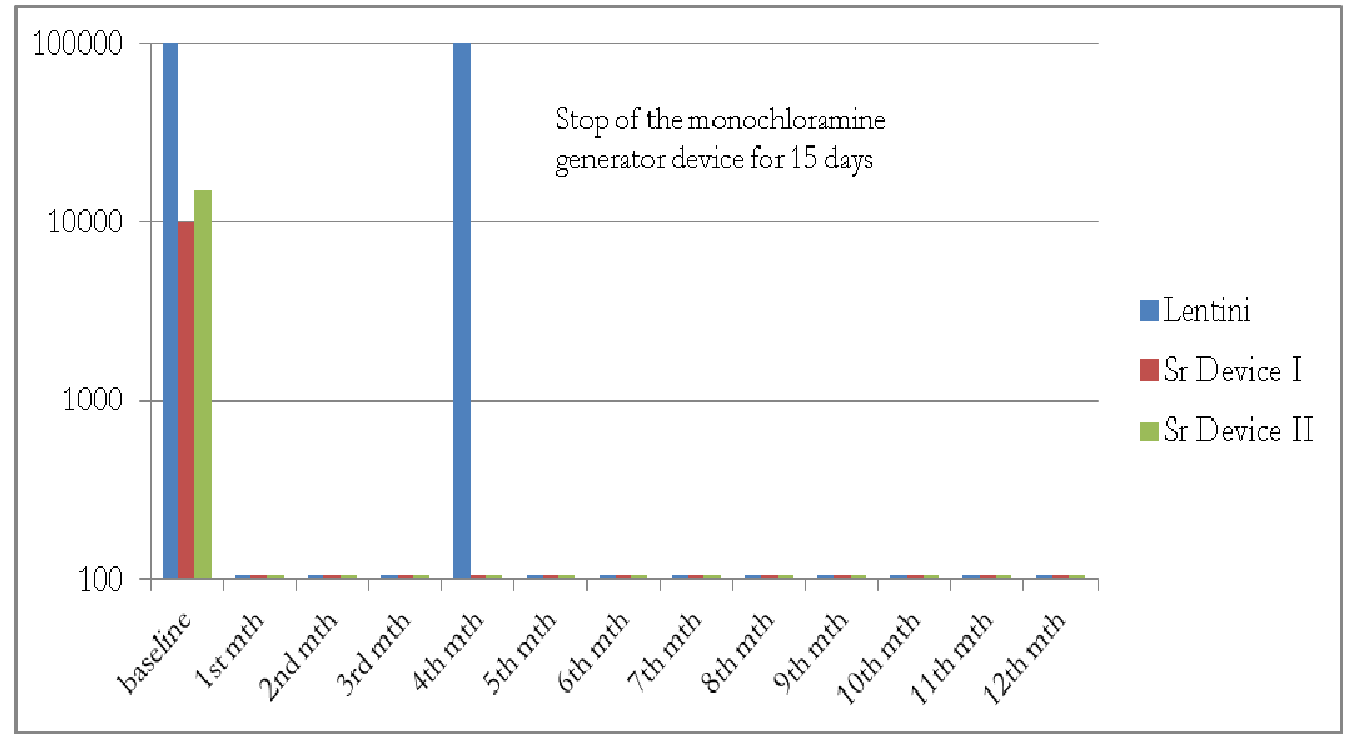

Fig. 1 Mean concentrations of $L$. pneumophila before and after the disinfection with monochloramine.

Table 1 Levels of ammonium, nitrates and nitrites before (baseline) and after the treatment of the domestic hot water with monochloramine.

\begin{tabular}{|c|c|c|c|c|c|c|c|c|c|c|}
\hline \multirow{2}{*}{ Hospital } & \multicolumn{10}{|c|}{ Ammonium $\mathrm{NH}_{4}^{+}$(limit $0.50 \mathrm{ppm}$ ) } \\
\hline & Feb & Mar & Apr & May & Jun & Jul & Aug & Sep & Oct & Nov \\
\hline & \multicolumn{10}{|c|}{ (baseline) } \\
\hline Hospital "Nuovo Ospedale di Lentini" & 0.05 & 0.48 & 0.32 & 0.29 & 0.25 & 0.21 & 0.44 & 0.50 & 0.11 & 0.15 \\
\hline \multicolumn{11}{|l|}{ Hospital "Umberto I" } \\
\hline Block 1 & 0.00 & 0.05 & 0.43 & 0.22 & 0.14 & 0.08 & 0.50 & 0.22 & n.d. & 0.35 \\
\hline Block 2 & 0.05 & 0.00 & 0.50 & 0.36 & 0.38 & 0.13 & 0.55 & 0.44 & 0.50 & 0.49 \\
\hline & \multicolumn{10}{|c|}{ Nitrites $\mathrm{NO}_{2-}$ (limit $0.50 \mathrm{ppm}$ ) } \\
\hline \multirow[t]{2}{*}{ Hospital } & Feb & Mar & Apr & May & Jun & Jul & Aug & Sep & Oct & Nov \\
\hline & \multicolumn{10}{|c|}{ (baseline) } \\
\hline Hospital "Nuovo Ospedale di Lentini" & 0.025 & n.d. & 0.002 & n.d. & 0.040 & n.d. & 0.008 & 0.027 & n.d. & 0.019 \\
\hline \multicolumn{11}{|l|}{ Hospital "Umberto I" } \\
\hline Block 1 & 0.025 & n.d. & 0.019 & n.d. & 0.017 & n.d. & 0.019 & 0.007 & n.d. & 0.003 \\
\hline Block 2 & 0.019 & n.d. & 0.024 & n.d. & 0.009 & n.d. & 0.021 & 0.011 & 0.003 & 0.009 \\
\hline & \multicolumn{10}{|c|}{ Nitrates $\mathrm{NO}_{3^{-}}$(limit $50 \mathrm{ppm}$ ) } \\
\hline \multirow[t]{2}{*}{ Hospital } & Feb & Mar & Apr & May & Jun & Jul & Aug & Sep & Oct & Nov \\
\hline & \multicolumn{10}{|c|}{ (baseline) } \\
\hline Hospital "Nuovo Ospedale di Lentini" & 17.0 & n.d. & 9.6 & n.d. & 4.6 & n.d. & 13.7 & 9.2 & n.d. & 5.7 \\
\hline \multicolumn{11}{|l|}{ Hospital "Umberto I" } \\
\hline Block 1 & 29.0 & n.d. & 13.2 & n.d. & 9.0 & n.d. & 15.9 & 21.4 & n.d. & 25.6 \\
\hline Block 2 & 30.0 & n.d. & 10.6 & n.d. & 8.7 & n.d. & 13.7 & 10.4 & 14.4 & 12.7 \\
\hline
\end{tabular}

\section{Discussion}

Twelve-months application of monochloramine in the DHW systems of the two hospitals heavily contaminated by L. pneumophila gave satisfactory results. The previous control procedures showed to be insufficient (increase of the temperature of water in boilers and shock hyperchlorination), effective but too expensive (point-of-use water filters) or absolutely ineffective $\left(\mathrm{H}_{2} \mathrm{O}_{2}\right)$ to control contamination. On the contrary, a significant decrease in Legionella percent positivity was observed in the two hospitals DHW following monochloramine application. In particular, 
in one of the two hospitals ("Nuovo Ospedale di Lentini"), only 1 week after the start of disinfection of the DHW with monochloramine, the percentages of positive sample points decreased at $8 \%$ with $L$. pneumophila lower than $10^{3} \mathrm{CFU} / \mathrm{L}$, suggesting that monochloramine is fully active since the beginning of its application.

The results are consistent with previous studies conducted both in Italy and the US. In particular, Marchesi et al. [4] observed a significant reduction of $L$. pneumophila from $97 \%$ positivity to $13.3 \%$ positivity after one year of monochloramine injection into a hospital WDS. Casini et al. [5] found that at the initial monitoring phase before the start of the monochloramine disinfection, all the sampling sites resulted positive for L. pneumophila, while no sample resulted positive after treatment. In the US, at the end of 1 year of a monochloramine injecting system evaluation Kandiah et al. [3] observed a reduction in water sample culture positivity rate from $53 \%$ to $0.35 \%$ for Legionella.

In the present study, at the hospital "Nuovo Ospedale di Lentini" the temporary stop of the monochloramine generator device increased the levels of L. pneumophila (ranging from more than $10^{2}$ to $10^{3}$ $\mathrm{CFU} / \mathrm{L}$ ), suggesting that keeping a stable concentration of monochloramine is mandatory to reduce the risk of hospital acquired legionellosis. This is consistent with Casini et al. [5], which found that all the samples became positive for $L$. pneumophila when the release of monochloramine was interrupted for around $24 \mathrm{~h}$ as a consequence of a failure of the disinfectant generator device. Anyway, the authors found that all samples became negative as soon as the system got back to operation.

Moreover, although HPC bacteria are not pathogenic and are not considered predictive of the presence or the absence of Legionella, they can be used for monitoring the disinfection system performance. Previous studies reported elevated HPC concentrations following several months of continuous monochloramine application [19]. The authors did not observe this trend during our investigation. In fact, average HPC concentrations decreased at undetectable levels following monochloramine application. Recently, Duda S. et al. [20] reported HPC reduction after DHW system chloramination of a US hospital which is consistent with our results.

Finally, although the aim of the authors' study was not to calculate cost-effectiveness, we noticed that the disinfection of DHW with monochloramine demonstrated to be a cost-saving procedure. In fact, only thanks to the decrease of the temperature in water boilers from $65-70{ }^{\circ} \mathrm{C}$ to $60{ }^{\circ} \mathrm{C}$ it was calculated a money saving of around 4.164,00€ (4.747,00\$) per year for the hospital "Nuovo Ospedale di Lentini" and of 7.988,00€ $(9.107,00 \$)$ per year for the hospital "Umberto I". These savings should be sufficient to at least compensate for the post-sale service and maintenance of the three monochloramine generators. It was not possible to evaluate the cost-saving of the applied technology in reducing the risk of infection because no nosocomial cases was detected, probably because L. pneumophila SG3 and SG6 are less frequently associated with legionellosis than SG1 [21].

In conclusion, the present study shows that the injection of monochloramine only on DHW at a concentration of $2.0-2.5 \mathrm{mg} / \mathrm{L}$ can be sufficient in controlling heavily contaminated hospitals WDS since the beginning of its application. Obviously, the method requires careful management to reach the right concentration of the disinfectant and to avoid changes in water chemical composition, in particular regarding the content of nitrite, nitrate and free ammonia and the production of DBPs.

\section{Conflict of Interest Statement}

Dr Stefano Melada, responsible for the Research \& Development department of Sanipur Srl, contributed with a scientific and technical support necessary for the development of the management plan. $\mathrm{He}$ did not participate to the samplings of the water, isolation and 

for the Control of Legionella Contamination in Italy

identification of legionellae. No financial support was given to the authors.

\section{References}

[1] Casini, B., Valentini, P., and Baggiani, A. 2008. "Molecular Epidemiology of Legionella Pneumophila Serogroup 1 Isolates Following long-Term Chlorine Dioxide Treatment in a University Hospital Water System." J. Hosp. Infect. 69: 141-7.

[2] Regulation (EU) no 528/2012 of the European parliament and of the council of 22 may 2012. Accessed September 10, 2014. http://eur-lex.europa.eu/LexUriServ/ LexUriServ.do?uri.

[3] Kandiah, A., Yassin, M. H., and Hariri, R. 2012. "Control of Legionella Contamination with Monochloramine Disinfection in a Large Urban Hospital Hot Water System." Am. J. Infect Control 40: e84.

[4] Marchesi, I., Cencetti, S., Marchegiano, P., Frezza, G., Borella, P., and Bargellini, A. "Control of Legionella Contamination in a Hospital Water Distribution System by Monochloramine." Am. J. Infect Control 40: 279-81.

[5] Casini, B., Buzzigoli, A., and Cristina, M. L. "Long-term Effects of Hospital Water Network Disinfection on Legionella and Other Waterborne Bacteria in an Italian University Hospital." Infect Control Hosp. Epidemiol 35: 293-9.

[6] Gazzetta Ufficiale della Repubblica Italiana. 2000. Italian guidelines for prevention and control of legionellosis. Italy.

[7] ISO (International Standard Organization) 19458: 2006. Water Quality-Sampling for Microbiological Analysis. Geneva.

[8] ISO (International Standard Organization) 6222. 1988. Water Quality. Enumeration of Viable Microorganisms. Colony Count by Inoculation in or on a Solid Medium. Geneva.

[9] ISO (International Standard Organization) 11731. 1988. Water Quality Detection and Enumeration of Legionella. Geneva.

[10] European Standard EN902:2009(E). 2009. Chemicals used for treatment of water intended for human consumption - Hydrogen peroxide. Brussels.

[11] Chord, F., Fascia, P., and Mallaval, F. 2011. "Chlorine dioxide for Legionella spp. Disinfection: Danger for Cross-Linked Polyethylene Pipes?" J. Hosp. Infect 78:
242-3.

[12] Devilliers, C., Fayolle, B., Laiarinandrasana, L., Oberti, S., and Gaudichet-Maurin, E. 2011. "Kinetics of chlorine-Induced Polyethylene Degradation in Water Pipes." Polymer Degradation and Stability 96: 1361-8.

[13] Yu, W., Azhdar, B., Andersson, D., Reitberger, T., Hassinen, J., Hjertberg, T., and Gedde, U. W. 2011. "Deterioration of Polyethylene Pipes Exposed to Water Containing Chlorine Dioxide." Polymer Degradation and Stability 96: 790-7.

[14] Yu, W., Sedghi, E., Nawaza, S., Hjertberg, T., Oderkerk, J., Costa, F. R., and Gedde, U. W. 2013. "Assessing the Long-Term Performance of Polyethylene Stabilised with Phenolic Antioxidants Exposed to Water Containing Chlorine Dioxide." Polymer Testing 32: 359-65.

[15] Zhang, Z., Stout, J. E., Yu, V. L., and Vidic, R. 2008. "Effect of Pipe Corrosion Scales on Chlorine Dioxide Consumption in Drinking Water Distribution Systems." Wat. Res. 42: 129-36.

[16] Hall, K. K., Giannetta, E. T., Getchell-White, S. I., Durbin, L. J., and Farr, B. M. 2003. "Ultraviolet Light Disinfection of Hospital Water for Preventing Nosocomial Legionella Infection: a 13-Year Follow-up." Infect Control Hosp. Epidemiol 24: 580-3.

[17] Ditommaso, S., Biasin, C., and Giacomuzzi, M. 2005. "Peracetic Acid in the Disinfection of a Hospital Water System Contaminated with Legionella Species." Infect Control Hosp Epidemiol 26: 490-3.

[18] Leoni, E., Sacchetti, R., Zanetti, F., and Legnani, P. P. 2006. "Control of Legionella Pneumophila Contamination in a Respiratory Hydrotherapy System with Sulfurous Spa Water." Infect Control Hosp. Epidemiol 27: 716-21.

[19] Pryor, M., Springthorpe, S., Riffard, S., Brooks, T., Huo, Y., Davis, G., and Sattar, S. A. 2004. "Investigation of Opportunistic Pathogens in Municipal Drinking Water under Different Supply and Treatment Regimes." Water Sci. Tech. 50: 83-90.

[20] Duda, S., Kandiah, S., Stout, J. E., and Baron, J. L. 2014. "Evaluation of a New Monochloramine Generation System for Controlling Legionella in Building Hot Water Systems." Infect Control Hosp Epidemiol 35 (11): 1356-63.

[21] Ditommaso, S., Giacomuzzi, M., and Biasin, C. 2007. "Incidence of Legionellosis in Hospitals Contaminated by Legionella Pneumophila other than Serogroup 1." Infect Control Hosp Epidemiol 28: 509-11. 